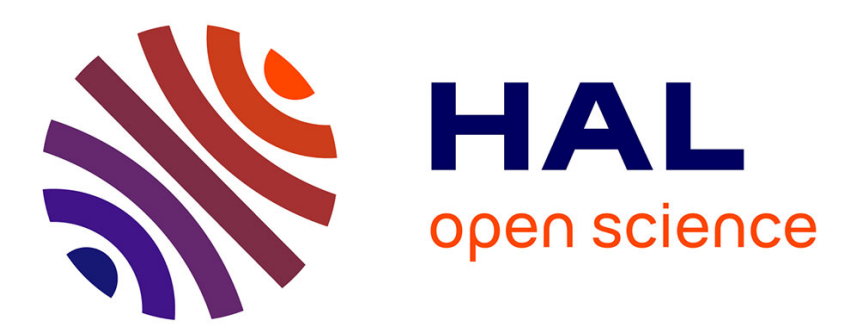

\title{
Role of the excited electronic states in the ionization of ambient air by a nanosecond discharge
}

\author{
Nicolas Minesi, Pierre Mariotto, Gabi D. Stancu, Christophe O Laux
}

\section{To cite this version:}

Nicolas Minesi, Pierre Mariotto, Gabi D. Stancu, Christophe O Laux. Role of the excited electronic states in the ionization of ambient air by a nanosecond discharge. AIAA Scitech 2020 Forum, Jan 2020, Orlando, United States. 10.2514/6.2020-0437 . hal-02431589

\section{HAL Id: hal-02431589 \\ https://hal.science/hal-02431589}

Submitted on 8 Jan 2020

HAL is a multi-disciplinary open access archive for the deposit and dissemination of scientific research documents, whether they are published or not. The documents may come from teaching and research institutions in France or abroad, or from public or private research centers.
L'archive ouverte pluridisciplinaire HAL, est destinée au dépôt et à la diffusion de documents scientifiques de niveau recherche, publiés ou non, émanant des établissements d'enseignement et de recherche français ou étrangers, des laboratoires publics ou privés. 


\title{
Role of the excited electronic states in the ionization of ambient air by a nanosecond discharge
}

\author{
N. Minesi ${ }^{1}$, P. Mariotto ${ }^{2}$, G. D. Stancu ${ }^{3}$ and C. O. Laux ${ }^{4}$ \\ EM2C, CNRS, CentraleSupélec, Université Paris Saclay, 3 Rue Joliot-Curie, 91190 Gif-sur-Yvette, France
}

In this paper, the mechanism of air ionization by a single nanosecond discharge under atmospheric conditions is studied by numerical simulations. The plasma kinetics is solved with ZDPlasKin and the electron energy distribution function is calculated with BOLSIG+. The originality of the model is to consider not only the excited electronic states

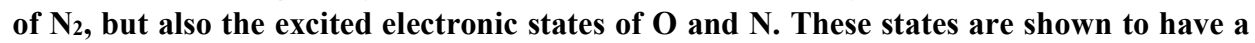
primary importance in the ionization of the plasma for $n_{e}>10^{17} \mathrm{~cm}^{-3}$. It is shown that a non-equilibrium plasma $\left(T_{e}>T_{\text {gas }}\right)$ at $n_{e}=10^{17} \mathrm{~cm}^{-3}$ can reach full ionization and thermalization $\left(T_{e}=T_{\text {gas }} \approx 3 \mathrm{eV}, n_{e} \approx 10^{19} \mathrm{~cm}^{-3}\right)$ in less than half a nanosecond under a field usually encountered in nanosecond discharges.

\section{Nomenclature}

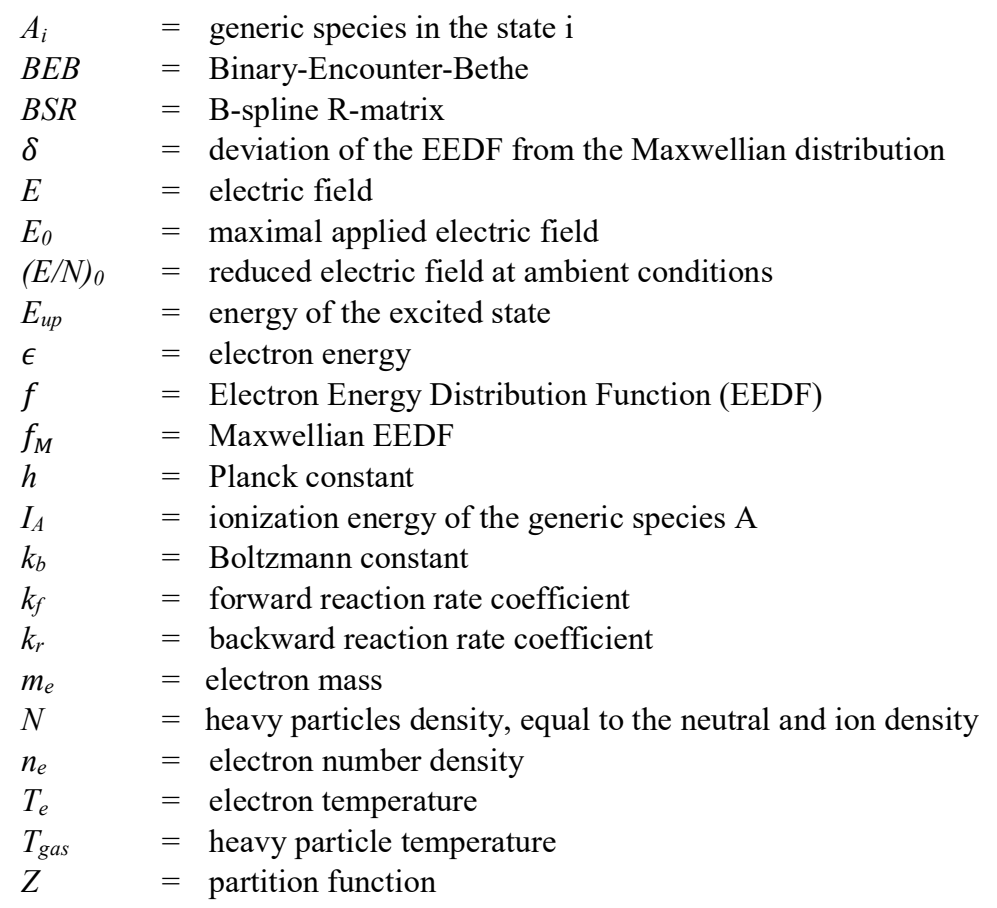

\footnotetext{
${ }^{1} \mathrm{PhD}$ Candidate, EM2C, CentraleSupélec, Université Paris-Saclay, nicolas.minesi@centralesupelec.fr

${ }^{2} \mathrm{PhD}$ Candidate, EM2C, CentraleSupélec, Université Paris-Saclay

${ }^{3}$ Professor, EM2C, CentraleSupélec, Université Paris-Saclay

${ }^{4}$ Professor, EM2C, CentraleSupélec, Université Paris-Saclay, Associate Fellow AIAA
} 


\section{Introduction}

Nanosecond Repetitively Pulsed (NRP) discharges are currently studied for their potential application such as plasma assisted combustion [1-4], control of thermo-acoustic instabilities [5] and ignition [6,7]. The knowledge of plasma properties prior to their introduction in industrial devices is important to predict their performances. NRP discharges have been known for being weakly ionized and out of equilibrium in preheated air [8-11]. The different states of non-equilibrium NRP plasmas (corona, glow and spark) have been described in [9]. Recently, the study of these discharges at ambient conditions has shown that NRP discharges can also be fully ionized. In $[12,13]$, Parkevitch et al. showed by laser interferometry that approximately one nanosecond after a $25-\mathrm{kV}$ voltage rise, a fully-ionized plasma is formed near the cathode surface in a pin-to-plane configuration. Moreover, they observed the formation of "clots" of dense plasma with electron number densities greater than $10^{20} \mathrm{~cm}^{-3}$. The typical dimension of these clots was around $1 \mu \mathrm{m}$. It was supposed that these clots arise from the explosion of the electrode material. In Ref. [14], Orriere et al. studied the formation of a plasma during a $2.5 \mathrm{kV}$ pulse of $10 \mathrm{~ns}$ in ambient air. The distance between the electrodes was $200 \mu \mathrm{m}$, and the maximum reduced field E/N was $600 \mathrm{Td}$ ( $1 \mathrm{Td}$ being equal to a field $\mathrm{E}=2.5 \times 10^{25} \mathrm{~V} / \mathrm{m}$ at $\mathrm{P}=1 \mathrm{~atm}$ and $\mathrm{T}=300 \mathrm{~K}$ ). The authors measured the electron number density by Stark broadening of $\mathrm{H}, \mathrm{O}$ and $\mathrm{N}$ atomic lines and measured a maximum density of $10^{19} \mathrm{~cm}^{-3}$. They also showed that due to the extremely high temperature $\left(\mathrm{T}_{\mathrm{e}}>30,000 \mathrm{~K}\right)$ of the plasma after the discharge, the electrons recombine with $\mathrm{O}^{+}$and $\mathrm{N}^{+}$(instead of $\mathrm{N}_{2}^{+}$or $\mathrm{NO}^{+}$as is the case in non-equilibrium plasmas [15]). Stark broadening was also used for electron number density measurement in several works in pin-to-pin or pinto-plane configuration [16-19] and all authors reported electron number densities higher than $10^{18} \mathrm{~cm}^{-3}$. Such a high electron number density was also reported in SDBD discharges [20-22]. The authors demonstrated that the increase of pressure can be responsible for the transition from a weakly ionized plasma (called "streamer") to a fully-ionized plasma (called "filament").

Simulations of partially ionized plasmas have already been performed [23] with the kinetic mechanism of Kossyi et al. [24] or Capitelli et al. [25] which are well suited for simulations of non-equilibrium plasmas. However, there is yet no chemical model describing the mechanism of full ionization by nanosecond discharges in air.

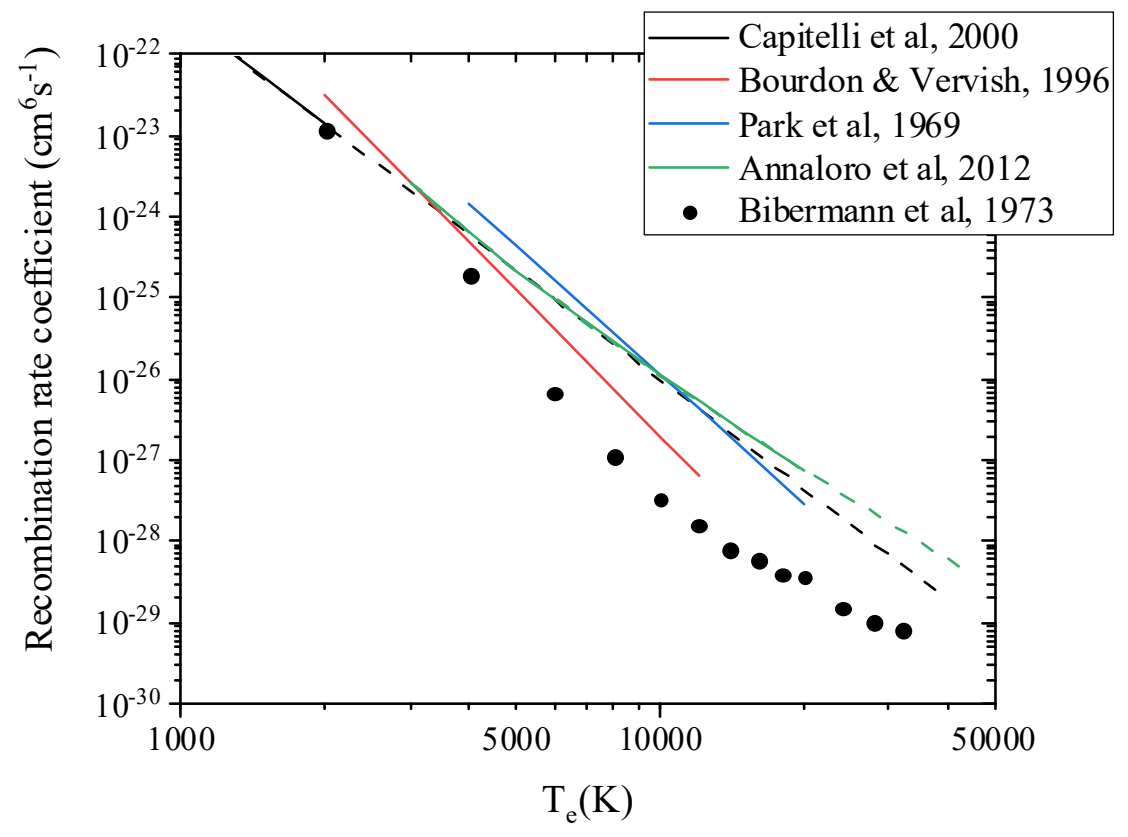

Fig. 1 Recombination rate coefficients from Ref. [26-29]. The rate coefficient reported by Capitelli et al. is for any ion, whereas the others are specific to $\mathrm{N}^{+}$. In these references, $\mathrm{N}^{+}\left({ }^{3} \mathrm{P}\right)$ recombines into the atomic ground state $\mathrm{N}\left({ }^{4} \mathrm{~S}\right)$. The solid lines indicate the validity range of the rate coefficients. The dashed lines correspond to extrapolations. 


\section{General view of the chemical mechanism}

Numerical simulations of the plasma kinetics under a given reduced field are performed using ZDPlasKin [30]. The kinetic model is based on a ready-to-use mechanism published by Flitti and Pancheshnyi [31] based on the work of Capitelli et al. [25]. This mechanism is intended to simulate nanosecond discharges out of equilibrium (i.e. $T_{\text {gas }} \ll T_{e}$ ). The Electron Energy Distribution Function (EEDF) is calculated by the Boltzmann equation solver BOLSIG+ [32]. The cross-sections of electron reactions are used to calculate the corresponding reaction rates and are taken mostly from the LXCat database [33-36]. Because excited states of molecular nitrogen can play a role in the ionization process [21], the ionization cross-sections of $\mathrm{N}_{2}^{*}$ are added, based on the work of Bacri and Medani [37]. The aim of this work being to simulate a fully ionized plasma, the ionization of atomic species and their reverse process must be included.

$$
A_{i}+e \rightleftharpoons A_{j}+e
$$

Reac. 1

For electronic transitions between the states $i$ and $j$ of species $A$, Reac. 1, the BOLSIG+ solver calculates forward and backward rate coefficients given the excitation cross-section and the ratio of the state degeneracies. This calculation is based on the detailed balance principle. In the case of ionization, Reac. 2, the backward rate coefficient is obtained by Eq. 1.

$$
\begin{array}{cc}
A+e \rightleftharpoons A^{+}+e+e & \text { Reac. } 2 \\
\frac{k_{f}}{k_{b}}=\frac{Z_{A^{+}} Z_{e}}{Z_{A} V} \exp \left(-\frac{\mathrm{I}_{A}}{k_{b} T_{e}}\right) & \text { Eq. } 1
\end{array}
$$

According to the law of mass action, the ratio of the forward and backward reaction rate coefficients of Reac. 2 is equal to the ratio of the partition functions divided by the volume, Eq. 1. It is assumed that the EEDF is Maxwellian (use of $T_{e}$ ) and that excited states of species A follow a Boltzmann distribution. Three-body recombination rates computed in various conditions are available in Ref. [26-29]. A recombination rate coefficient valid for any ion is calculated by Bibermann et al. in Ref. [38]. This coefficient is proportional to $T_{e}^{-4.5}$ and said to be valid if $T_{e}$ is smaller than the energy of the first excited state of the considered atom. This rate coefficient is later reported by Capitelli et al. and its validity is limited to $2000 \mathrm{~K}$ [25]. Its evolution is plotted in Fig. 1. Bibermann et al. also calculated the $\mathrm{N}^{+}$recombination rate coefficients at several temperatures (reported in Fig. 1). The deviation between the $T_{e}^{-4.5}$ law and the $\mathrm{N}^{+}$recombination rate coefficient begins at $T_{e} \sim 2000 \mathrm{~K}$ which justifies the more restrictive limit of Capitelli et al. A review of other $\mathrm{N}^{+}$three-body recombination rates can be found in [29].

The use of these recombination rates implies that $\mathrm{N}^{+}$always recombines into the ground state of $\mathrm{N}$. However, recombination into excited electronic states should be considered. It is also shown in Fig. 1 that recombination rates of different sources can differ by two orders of magnitude. Therefore, the model will be electronic statespecific, and the recombination rates will be computed by detailed balance using state-specific ionization crosssection or using state-specific reaction rate coefficients (detailed in next section).

In all simulations performed in this work, the initial gas temperature is equal to $300 \mathrm{~K}$ and the initial electron temperature to $1000 \mathrm{~K}$. The initial total gas density $\left(79 \%\right.$ of $\mathrm{N}_{2}$ and $21 \%$ of $\left.\mathrm{O}_{2}\right)$ is equal to the Loschmidt number at $300 \mathrm{~K}, n_{\text {Los }}=2.45 \times 10^{19} \mathrm{~cm}^{-3}$. The initial electron density is equal to $n_{e 0}=10^{10} \mathrm{~cm}^{-3}$. The integration step is below 10 ps. The nanosecond pulse is modeled with two phases:

1. For $t=0-1 \mathrm{~ns}$, the applied field increases linearly with time up to its maximum value.

2. For $t=1-15 \mathrm{~ns}$, the applied field is constant.

3. At $t=15 \mathrm{~ns}$, the simulation is stopped.

This is summarized in Eq. 2 where $E_{0}$ is the applied field. 


$$
\begin{gathered}
\mathrm{E}\left[\mathrm{V} . \mathrm{cm}^{-1}\right]= \begin{cases}E_{0} \times \frac{t}{1 \mathrm{~ns}}, \quad t \leq 1 \mathrm{~ns} \\
E_{0}, \quad 1 \mathrm{~ns} \leq t \leq 15 \mathrm{~ns}\end{cases} \\
E /{ }_{N}[\mathrm{Td}]=\frac{E\left[\mathrm{~V} \cdot \mathrm{cm}^{-1}\right]}{N\left[\mathrm{~cm}^{-3}\right]} \times 10^{17} \text { Eq. } 2
\end{gathered}
$$

If not specified, $E_{0}=56 \mathrm{kV} \cdot \mathrm{cm}^{-1}$, corresponding to $(E / N)_{0}=230 \mathrm{Td}$ in ambient conditions. This generic pulse is representative of a $6-\mathrm{kV}$ pulse applied across a 1-mm gap. Because BOLSIG+ is adapted for partially ionized plasma, the reduced field $\mathrm{E} / \mathrm{N}$ is usually equal to be the ratio of the electric field to the neutral particle density. In this work, the neutral particle density can drop to negligible values and the reduced field tends toward infinity. Therefore, we set $\mathrm{N}$ as the heavy particle density, i.e. equal to the density of neutral and ions. At $n_{e}<10^{18} \mathrm{~cm}^{-3}$, this assumption induces negligible variations in the results. At $n_{e}>10^{18} \mathrm{~cm}^{-3}$, the simulations are marked by a dotted line (instead of a full line) to indicate these results are subject to the previous assumption. Because this simulation is 0 -D, field screening effects such as the electrode fall are not considered.

Table 1 Excited levels of $\mathrm{N}$ and $\mathrm{O}$ included in the present work. The excitation rate coefficients between states is computed with BOLSIG+ based on the BSR cross-sections calculated in Ref. [39,40]. When available, the ionization BSR cross-sections are used, otherwise, the reaction rates computed in Ref. [41] on

\begin{tabular}{|c|c|c|c|c|c|c|}
\hline & Configuration & Term & $\mathrm{g}$ & $E_{u p}(\mathrm{eV})$ & Electronic transitions rate & Ionization rate \\
\hline \multirow{8}{*}{$\mathrm{N}$} & $2 \mathrm{~s}^{2} 2 \mathrm{p}^{3}$ & ${ }^{4} \mathrm{~S}^{0}$ & 4 & 0 & \multirow{8}{*}{$\begin{array}{l}\text { Integral of BSR cross- } \\
\text { section [39] }\end{array}$} & \multirow{3}{*}{$\begin{array}{c}\text { Integral of BSR } \\
\text { cross-section } \\
{[39]}\end{array}$} \\
\hline & $2 s^{2} 2 p^{3}$ & ${ }^{2} \mathrm{D}^{0}$ & 10 & 2.38 & & \\
\hline & $2 s^{2} 2 p^{3}$ & ${ }^{2} \mathrm{P}^{0}$ & 6 & 3.575 & & \\
\hline & $2 s^{2} 2 p^{2}\left({ }^{3} P\right) 3 s$ & ${ }^{4} \mathrm{P}$ & 12 & 10.33 & & \multirow{5}{*}{$\begin{array}{c}\text { Arrhenius rate } \\
{[41]}\end{array}$} \\
\hline & $2 s^{2} 2 p^{2}\left({ }^{3} P\right) 3 s$ & ${ }^{2} \mathrm{P}$ & 6 & 10.68 & & \\
\hline & $2 s^{2} 2 p^{4}$ & ${ }^{4} \mathrm{P}$ & 12 & 10.92 & & \\
\hline & $2 s^{2} 2 p^{2}\left({ }^{3} P\right) 3 p$ & ${ }^{2} S^{0}$ & 2 & 11.60 & & \\
\hline & $2 s^{2} 2 p^{2}\left({ }^{3} P\right) 3 p$ & ${ }^{4} \mathrm{D}^{0}$ & 20 & 11.75 & & \\
\hline \multirow{3}{*}{$\mathrm{O}$} & $2 s^{2} 2 p^{4}$ & ${ }^{3} \mathrm{P}$ & 9 & 0 & \multirow{3}{*}{\multicolumn{2}{|c|}{ Integral of BSR cross-section [40] }} \\
\hline & $2 s^{2} 2 p^{4}$ & ${ }^{1} \mathrm{D}$ & 5 & 1.97 & & \\
\hline & $2 s^{2} 2 p^{4}$ & ${ }^{1} \mathrm{~S}$ & 1 & 4.19 & & \\
\hline
\end{tabular}
the basis of BEB cross-sections are used. All reverse rates are calculated by detailed balancing.

\section{Determination of ionization and recombination rates}

In this section, the procedure to determine the recombination rate coefficients is detailed. If each electronic level of the species is considered, only the EEDF has to be Maxwellian to apply detailed balancing. The partition function of each level is simply its degeneracy multiplied by the exponential factor. In this work, we only consider the ground state of the ions, $\mathrm{N}^{+}\left({ }^{3} \mathrm{P}\right)$ and $\mathrm{O}^{+}\left({ }^{4} \mathrm{~S}\right)$.

$$
\begin{array}{cc}
A_{i}+e \rightleftharpoons A^{+}+e+e & \text { Reac. } 3 \\
\frac{d\left[A_{i}\right]}{d t}=-\frac{d\left[A^{+}\right]}{d t}=k_{r, i}\left[A^{+}\right] n_{e}^{2} & \text { Eq. } 4 \\
\frac{d\left[A^{+}\right]}{d t}=-\frac{d\left[A_{i}\right]}{d t}=k_{f, i}\left[A_{i}\right] n_{e} & \text { Eq. } 5
\end{array}
$$


The electronic state-specific forward and backward rate coefficients of Reac. 3 are defined in Eq. 4 and Eq. 5. The forward rate coefficients are calculated in BOLSIG+ based on the cross-sections of the reactions. According to the detailed balance principle, it is possible to express $k_{r, i}$ in Eq. 6.

$$
k_{r, i}=\frac{1}{2}\left(\frac{2 \pi m_{e} k_{b} T_{e}}{h^{2}}\right)^{\frac{-3}{2}} \frac{g_{A_{i}}}{g_{A^{+}}} \exp \left(\frac{\mathrm{I}_{\mathrm{A}}-E_{A_{i}}}{k_{b} T_{e}}\right) k_{f, i} \quad \text { Eq. } 6
$$

This procedure has been applied to the first 8 electronic levels of atomic nitrogen and first 3 electronic levels of atomic oxygen. These levels are listed in Table 1 and are all included in the chemical mechanism if not specified. The excitation cross-sections by electron impact between states of atomic oxygen and nitrogen are taken from Refs. [39] and [40]. The ionization cross-sections by electron impact of the first three levels of oxygen and nitrogen are also calculated in Refs. [39] and [40]. The ionization rates of nitrogen levels above $10 \mathrm{eV}$ are calculated using the reaction rate coefficients calculated from BEB cross-sections in Ref. [41] for $T_{e}$ up to 50,000 $\mathrm{K}$. These rate coefficients are function of $T_{e}$ and the EEDF is therefore assumed to be Maxwellian when these rates are dominant.

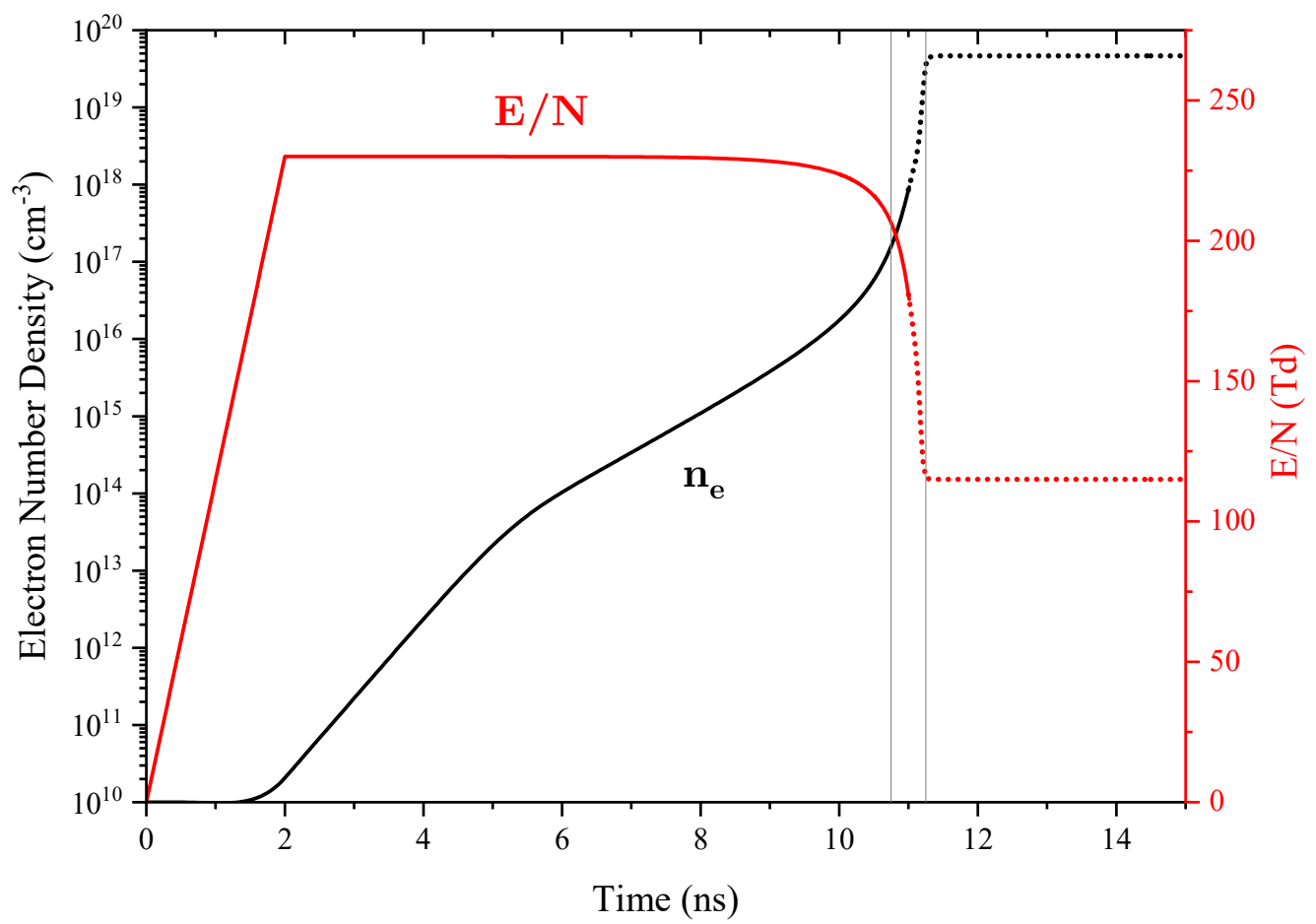

Fig. 2 Variation of the electron number density during the 15-ns pulse (black line). The decrease of the reduced electric field (red line) is due to the increase of heavy particles' density during dissociation. The region of fast ionization is delimited by the gray lines between 10.75 and $11.25 \mathrm{~ns}$. 


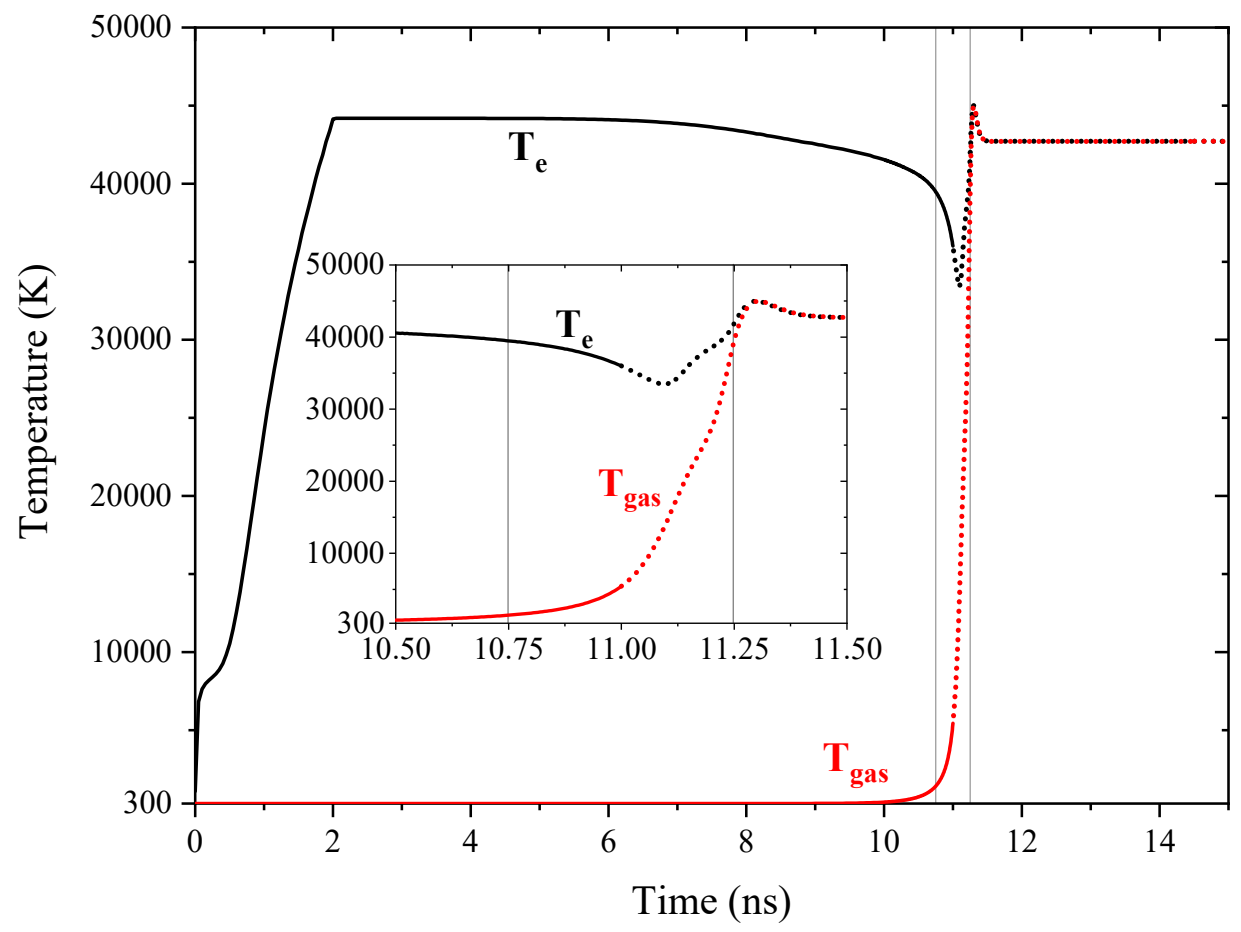

Fig. 3 Evolution of the electron and gas temperatures (black and red, respectively). The fast increase of gas temperature occurs between the gray lines at 10.75 and $11.25 \mathrm{~ns}$.

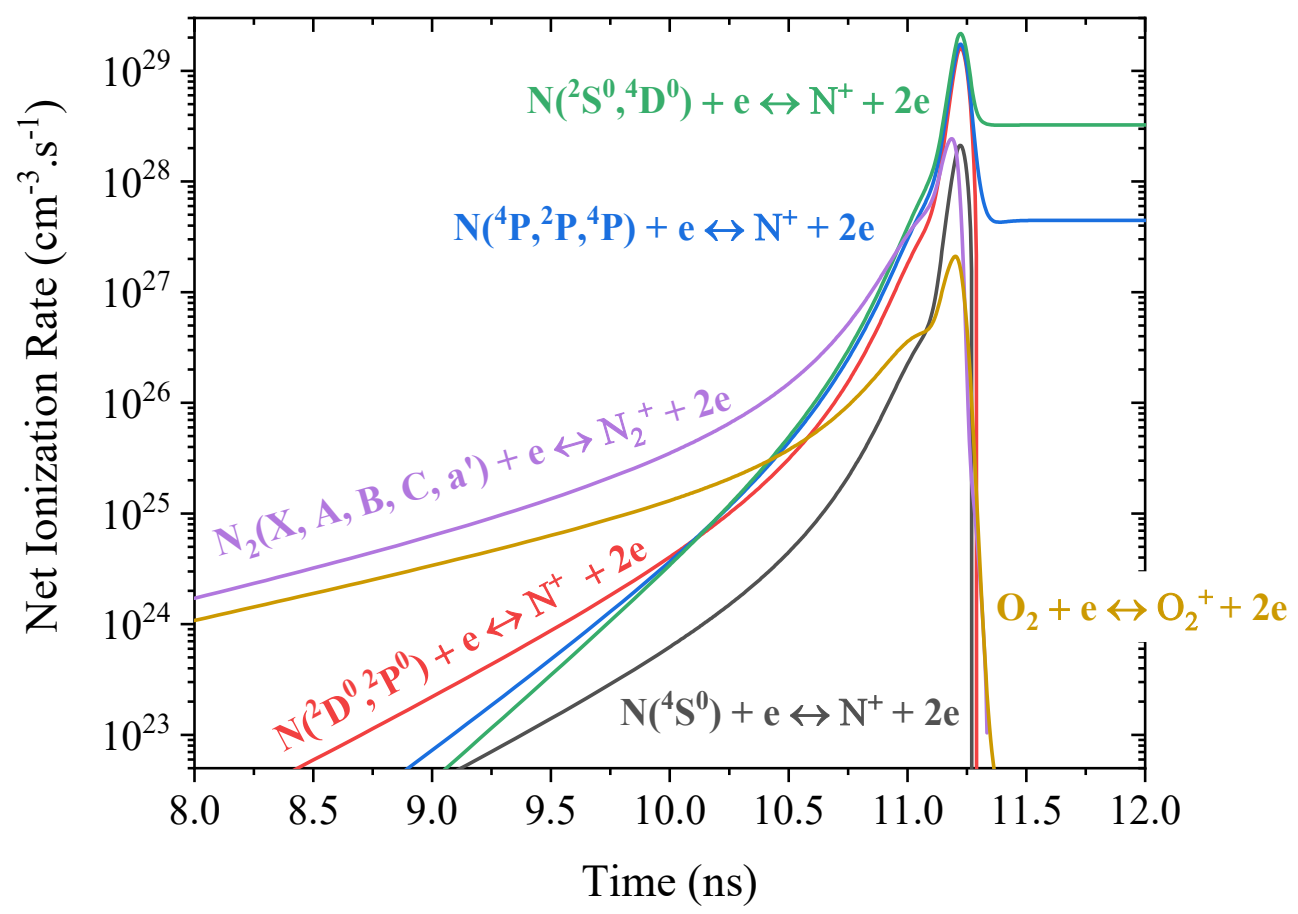

Fig. 4 Net rates of ionization (backward rates subtracted). For the sake of clarity, the net ionization rates of the two metastable states of $\mathrm{N}$ at 2.38 and $3.57 \mathrm{eV}$, red curve, are grouped. The next 5 levels are gathered in two groups: blue curve $(10.33,10.68,10.92 \mathrm{eV})$ and green curve $(11.60$ and $11.75 \mathrm{eV})$. 
Table 2 Plasma parameters before $(t=10.75 \mathrm{~ns})$ and after $(t=11.25 \mathrm{~ns})$ the fast ionization phase. At $t=11.25 \mathrm{~ns}, 36 \%$ of atomic nitrogen is in the ground state $\left(2.7 \times 10^{18} \mathrm{~cm}^{-3}\right)$.

\begin{tabular}{|c||c|c|c|c|c|c|}
\hline $\mathrm{t}(\mathrm{ns})$ & $\mathrm{E} / \mathrm{N}(\mathrm{Td})$ & $T_{e}(\mathrm{~K})$ & $T_{\text {gas }}(\mathrm{K})$ & $\mathrm{N}_{2}\left(\mathrm{~cm}^{-3}\right)$ & $\mathrm{N}\left(\mathrm{cm}^{-3}\right)$ & $n_{e}\left(\mathrm{~cm}^{-3}\right)$ \\
\hline \hline 10.75 & 207.0 & 39600 & 1400 & $1.6 \times 10^{19}$ & $4.7 \times 10^{18}$ & $1.6 \times 10^{17}$ \\
\hline 11.25 & 116.9 & 41300 & 38000 & $7.8 \times 10^{15}$ & $7.4 \times 10^{18}$ & $3.3 \times 10^{19}$ \\
\hline
\end{tabular}

\section{Ionization mechanism}

The reduced field, Eq. 3, is expected to follow the variation of E. However, at the onset of $\mathrm{N}_{2}$ and $\mathrm{O}_{2}$ dissociation, the total gas density increases, implying a decrease of E/N. This effect is shown in Fig. 2 where a generic field of $237 \mathrm{Td}$ is applied. At $t=12 \mathrm{~ns}$, the reduced field begins to decay due to molecular dissociation. Shortly after, the atoms are ionized, and $\mathrm{E} / \mathrm{N}$ is constant.

In the chemical mechanism, no heating is associated with the exothermic (or endothermic) reactions. However, the heat exchange due to electron-neutral and electron-ion elastic collisions is computed by BOLSIG+. In nonequilibrium discharges, the electron number density is lower $\left(n_{e}=10^{15}-10^{16} \mathrm{~cm}^{-3}\right)$ and the temperature increases $(\Delta T \approx 1000 \mathrm{~K})$ mainly due to the ultrafast heating mechanism [11]. Models to determine the temperature evolution of non-equilibrium discharges are already available in the literature [42]. In the case of a thermal spark i.e. a fully ionized nanosecond spark, the heating induced by electron collisions is dominant. The temperature evolution is demonstrated in Fig. 3. While the plasma is partially ionized, the electron temperature is constant around $T_{e}=45,000 \mathrm{~K}$. The gas (heavy) temperature remains equal to $T_{\text {gas }}=300 \mathrm{~K}$. The heavy particles and the electrons start their thermalization at $\mathrm{t}=10.5 \mathrm{~ns}$, when the electron number density starts to increase. The decrease of the reduced field (due to molecules dissociation) induces a decrease of $T_{e}$ from 40,000 K to $35,000 \mathrm{~K}$. At $t=11.25 \mathrm{~ns}, T_{\text {gas }}$ being close to $T_{e}$, less energy is transferred from the electron to the heavy particles and $T_{e}$ increases by $7000 \mathrm{~K}$. Soon after, at $t=12 \mathrm{~ns}$, the electrons finally thermalize with the heavy particles at $T_{\text {gas }}=T_{e}=42,000 \mathrm{~K}$.

The electron production is first dominated by the ionization of $\mathrm{N}_{2}$ and $\mathrm{O}_{2}$, see Fig. 4. In the appendix, the evolution of the density of $\mathrm{N}_{2}$ excited states is plotted and the importance $\mathrm{N}_{2}$ (a') ionization is discussed. The ionization rates of $\mathrm{N}_{2}(\mathrm{~A}, \mathrm{~B}, \mathrm{C})$ are lower by an order of magnitude compared to the ground state. Fig. 4 distinguishes the net contribution to the production of electrons from the different states of $\mathrm{N}$. For $t$ in the range $10.75-11.25 \mathrm{~ns}$, the electrons are mainly produced by electron-impact ionization of highly excited states of $\mathrm{N}$. At $t=11.25 \mathrm{~ns}$, the gas is ionized at $\sim 83 \%$. The plasma parameters at the transition from a non-equilibrium to a thermalized plasma are summarized in Table 2. It is shown that the electron number density gains two orders of magnitude in less than $0.5 \mathrm{~ns}$. At the end of the pulse the electron number density saturates to $5 \times 10^{19} \mathrm{~cm}^{-3}$. The plasma recombination phase has not been studied and is part of future work.

\section{EEDF deviation from the Maxwellian distribution}

The EEDF is computed by BOLSIG+ considering the total cross-section of the plasma mixture. Departure from a Maxwellian distribution is expected in non-equilibrium plasmas generated by nanosecond discharges. The transition between $t=10.75 \mathrm{~ns}$ and $t=11.25 \mathrm{~ns}$ marks the thermalization of the electron and heavy temperatures and a set of EEDF calculated in this interval are shown in Fig. 5. The deviation from the Maxwellian distribution is quantified in Eq. 7, where $f(\epsilon)$ is the EEDF and $f_{M}(\epsilon)$ is the corresponding Maxwellian distribution with the same averaged energy. Compared to the equivalent Maxwellian distribution, the EEDF is first overpopulated at approximately $10 \mathrm{eV}$. From $t=10.9 \mathrm{~ns}$ to $t=11.25 \mathrm{~ns}$, the peak is shifted to higher energies and flattens. This shift can be due to the peak of atomic nitrogen effective cross-section at $10 \mathrm{eV}$. At $t=11.5 \mathrm{~ns}$, the EEDF is Maxwellian $(\delta(\epsilon)=1$ for $\epsilon<20 \mathrm{eV})$ due to the electron-electron collisions.

$$
\delta(\epsilon)=\frac{f(\epsilon)}{f_{M}(\epsilon)}
$$


The recombination rates are calculated by detailed balancing, assuming the EEDF to be Maxwellian. However, the recombination rates are not significant during the ionization phase. Therefore, the approximation of the latter assumption is sufficient for results below $\mathrm{t}<10.25 \mathrm{~ns}$. In Fig. 4, the net ionization rates of the nitrogen states are compared. The rates of $\mathrm{N}\left({ }^{4} \mathrm{~S}\right), \mathrm{N}\left({ }^{2} \mathrm{D}\right)$ and $\mathrm{N}\left({ }^{2} \mathrm{P}\right)$ ionization, computed by BOLSIG + , are accurate given the precision of the BSR cross-section. The recombination in these three states becomes significant at $t=11.25 \mathrm{~ns}$, as the EEDF is getting close to a Maxwellian. It is therefore valid to use detailed balancing to calculate the recombination rates.

The rates of the higher excited states ionization are Arrhenius laws based on BEB cross-sections integrated assuming a Maxwellian EEDF [41]. This assumption could have an impact on the results if the EEDF strongly deviates from the Maxwellian. During the interval $10.75-11.25 \mathrm{~ns}$, the ionization of $\mathrm{N}^{*}\left(E_{u p}>10 \mathrm{eV}\right)$ is dominant, but the EEDF is quickly becoming Maxwellian. The approximation is therefore assumed to be valid on this time interval. More accurate calculations would require the direct integration of the BEB cross-section instead of the Arrhenius rates. This possibility is currently explored in our group for future work. After $t=11.5 \mathrm{~ns}$, the EEDF is Maxwellian and the application of the Arrhenius rates is therefore accurate.

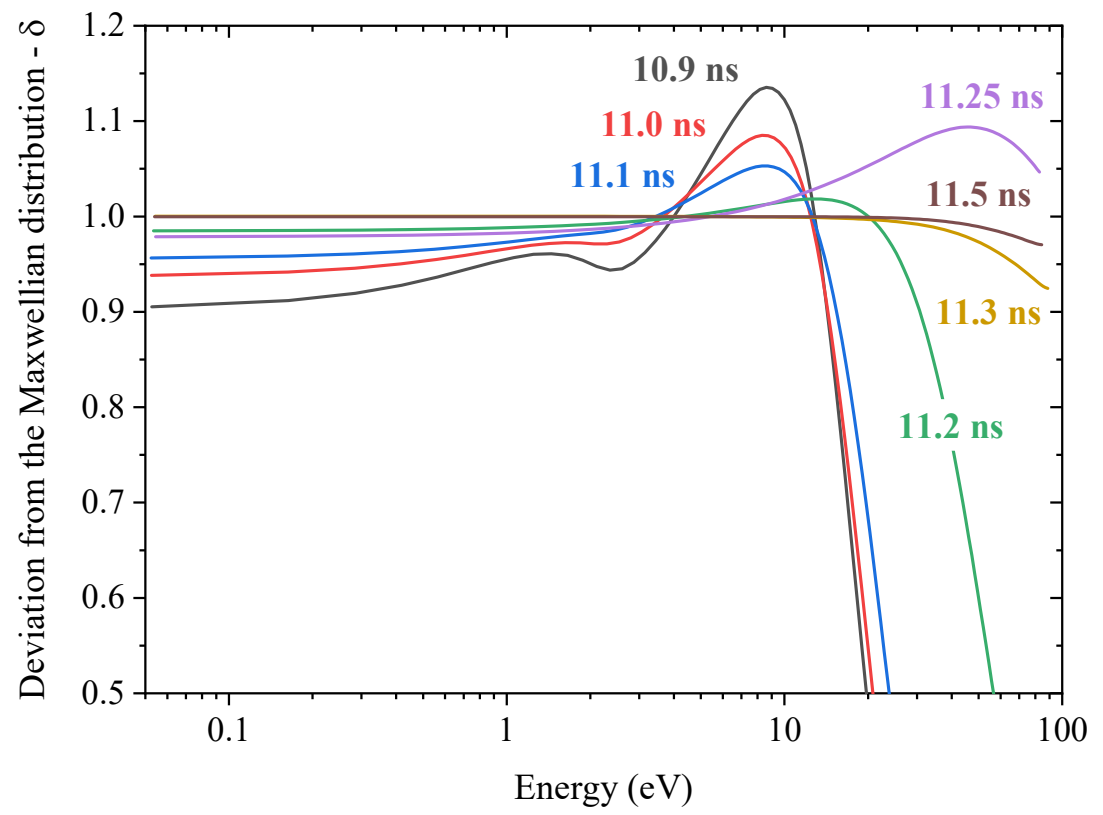

Fig. 5 Deviation of the EEDF ( $\delta$ ) from a Maxwellian EEDF of the same average energy 


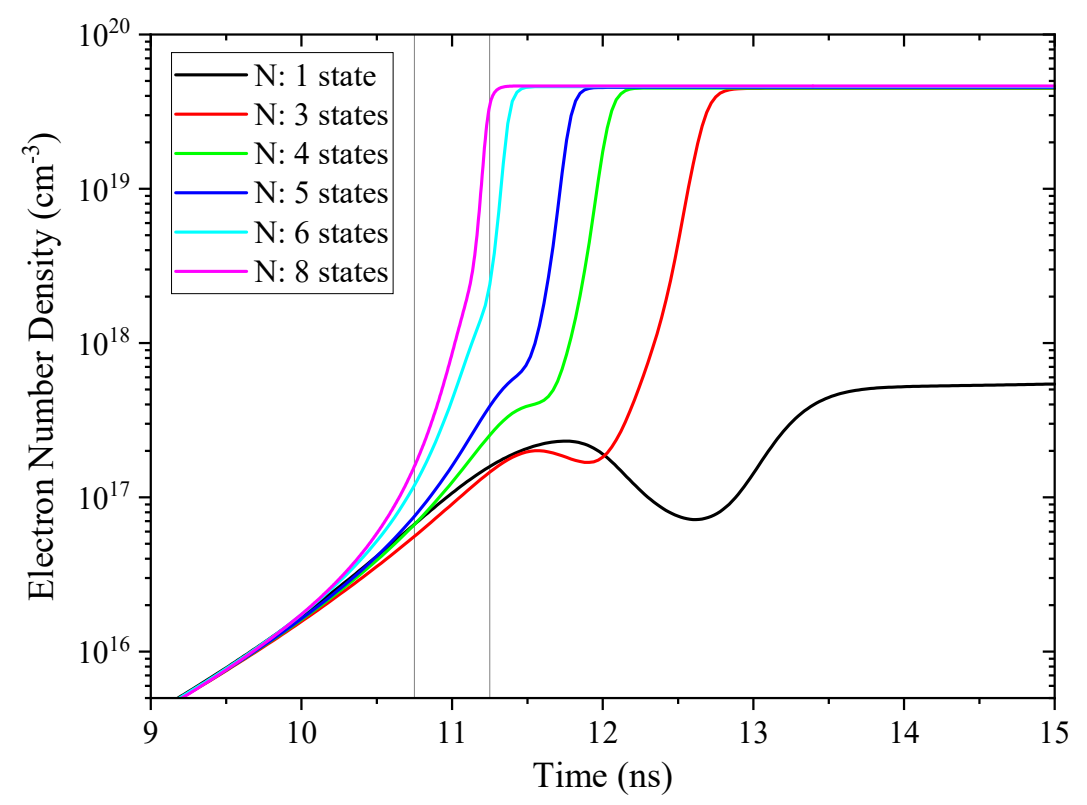

Fig. 6 Temporal evolution of the electron number density for simulations including one, three, four, five six, and eight states of atomic nitrogen (black, red, green, blue, cyan and purple respectively). Three states of atomic oxygen are included in the simulations except for the black curve (ground state only). The region of fast ionization (full model including 8 excited states of nitrogen) is delimited by the gray lines at 10.75 and $11.25 \mathrm{~ns}$.

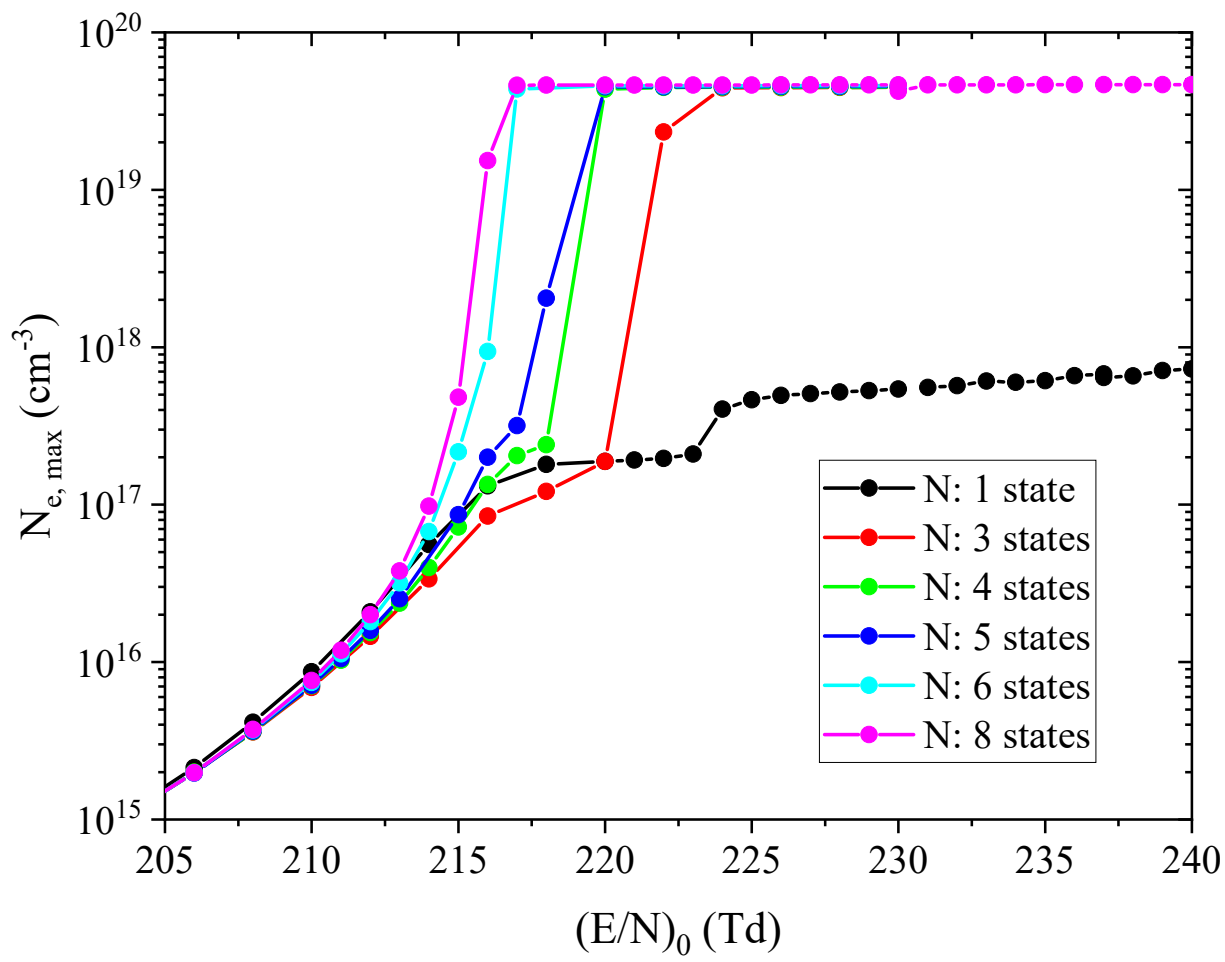

Fig. 7 Maximal electron number density after the generic pulse of $15 \mathrm{~ns}$ of $(\mathrm{E} / \mathrm{N})_{0}$. Three states of atomic oxygen are included in the simulations except for the black curve (ground state only). 


\section{Influence of the number of atomic states in the model}

The nitrogen excited electronic states have shown a real influence on the electron production. This was already seen when the excited states of molecular nitrogen were included in Ref. [21]. New simulations are performed changing the number of nitrogen and oxygen excited states included in the chemical mechanism. The applied reduced field is equal to $(\mathrm{E} / \mathrm{N})_{0}=230 \mathrm{Td}$ in ambient conditions. The evolution of the electron number density is showed in Fig. 6, for $t>9$ ns. The 8-levels (full) model will be the reference of comparison. If only six excited states of nitrogen $\left(\mathrm{E}_{\text {up }}<11.61 \mathrm{eV}\right.$ in Table 1$)$ are included, a similar ionization that described in previous sections is encountered. However, if only the three first levels of nitrogen are included, the total ionization of the gas is delayed by $1 \mathrm{~ns}$. An intermediate result is obtained if four or five levels are included. If only the ground states of nitrogen and oxygen are included in the simulation, the maximal (final) electron number density is decreased by two orders of magnitude compared to the reference. These results show again the dynamics of the thermal spark formation is strongly influence by the presence of atomic excited states in the simulation. The deviation between the models starts at $t=10-10.5 \mathrm{~ns}$, corresponding to $n_{e}=10^{16}-10^{17} \mathrm{~cm}^{-3}$.

Following, the previous procedure, several simulations are performed for different $(\mathrm{E} / \mathrm{N})_{0}$ varying the number of excited states included in the simulation. The maximal electron number density (reached at the end of the pulse) is shown in Fig. 7. As before, the two excited levels of atomic oxygen, $\mathrm{O}\left({ }^{1} \mathrm{D},{ }^{1} \mathrm{~S}\right)$, are not included if only the nitrogen ground state is used. For $\mathrm{E} / \mathrm{N}<213 \mathrm{Td}$, the deviation between all the models is relatively small. The 8levels model shows full ionization is reached for $(\mathrm{E} / \mathrm{N})_{0}>216 \mathrm{Td}$. The deviation with the reference of the 6-model is small on the entire studied range. If only three excited states of nitrogen are included, the full ionization is reached for $(\mathrm{E} / \mathrm{N})_{0}>224 \mathrm{Td}$. If only the ground states of nitrogen and oxygen are included, the electron number density reaches $10^{19} \mathrm{~cm}^{-3}$ for $(\mathrm{E} / \mathrm{N})_{0}>260 \mathrm{Td}$ (not shown in Fig. 7). In term of electron number density, the deviation between the different models is marked at a value of $n_{e} \sim 10^{17} \mathrm{~cm}^{-3}$. The same value is encountered in Fig. 6 when the models do not agree with each other's at $t=10-10.5 \mathrm{~ns}$. We therefore conclude that the correct description of the plasma dynamics must include at least the first six electronic states of atomic nitrogen, if $n_{e}>$ $10^{17} \mathrm{~cm}^{-3}$.

\section{Conclusion}

The mechanism of ionization in ambient air by a generic $15-\mathrm{ns}$ pulse of $56 \mathrm{kV} \cdot \mathrm{cm}^{-1}$ is studied with 0 -D simulations using ZDPlaskin and BOLSIG+. The electron production phase is first dominated, as usual, by electron-impact ionization of $\mathrm{N}_{2}$ and $\mathrm{O}_{2}$. Then, molecules dissociate, and the density of atomic species increases. Excited electronic states of atoms and molecules are populated by electron-impact excitation. We show that the ionization from $\mathrm{N}_{2}$ (a'), $\mathrm{N}$ and $\mathrm{N}^{*}$ soon becomes more important than ionization from the ground states of $\mathrm{N}_{2}$ and $\mathrm{O}_{2}$. We also show that ionization from the excited $\mathrm{N}$ states with energy greater than $10 \mathrm{eV}$ quickly dominates. The electron number density increases by two orders of magnitude (from $10^{17}$ to more than $10^{19} \mathrm{~cm}^{-3}$ ) in less than half a nanosecond. Simultaneously, the gas temperature increases from 300 to $42,000 \mathrm{~K}$ and equilibrates with the electron temperature. The EEDF is found to be Maxwellian by the time the plasma is fully ionized. This mechanism explains in our opinion the fast transition $(<1 \mathrm{~ns})$ from a non-equilibrium to a thermal plasma as experimentally observed with nanosecond discharges in Refs. [17,21,43].

\section{Appendix}

We show in Fig. 8 the evolution of the main species involved in the ionization mechanism. The transition between a non-equilibrium to a thermal plasma is marked by two grey lines in Fig. 8 at 10.75 and 11.25 ns. During this transition, $\mathrm{N}_{2}$ is completely dissociated. The excited states of $\mathrm{N}_{2}$ are also completely dissociated. The evolution of $\mathrm{N}_{2}\left(\mathrm{a}^{\prime}\right)$ is however surprisingly peaked compared to the other excited states. This is due to the differences in the dissociation cross-sections showed in Fig. 9. As the energy of the electrons increases, the dissociation of $\mathrm{N}_{2}$ excited states is expected before their ionization. However, the dissociation cross-section of $\mathrm{N}_{2}$ (a') in Fig. 9 is low compared to the other excited states. $\mathrm{N}_{2}\left(\mathrm{a}^{\prime}\right)$ is therefore less affected by electron-impact dissociation and is efficiently ionized compared to $\mathrm{N}_{2}$ other states. This is shown in Fig. 10 where the ionization rates are plotted against time. For $t>10 \mathrm{~ns}$, the ionization rate of $\mathrm{N}_{2}\left(\mathrm{a}^{\prime}\right)$ is higher than the ionization rate $\mathrm{N}_{2}(\mathrm{X})$. 


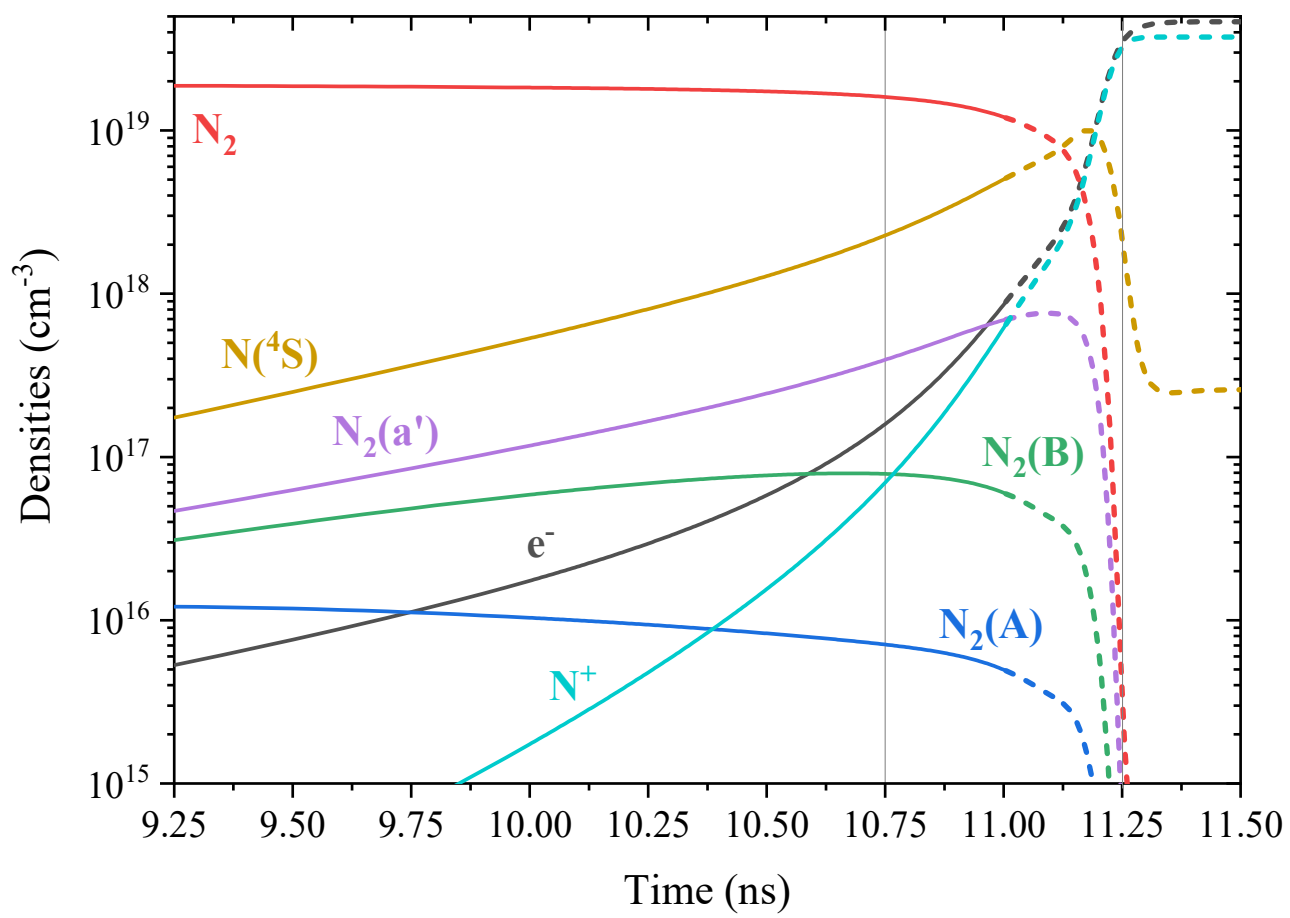

Fig. 8 Evolution of the species density during the generic $15-\mathrm{ns}$ pulse of $E_{0}=56 \mathrm{kV} \cdot \mathrm{cm}^{-1}$ according to the 8-levels model. The region of fast ionization is delimited by the gray lines between 10.75 and $11.25 \mathrm{~ns}$. 


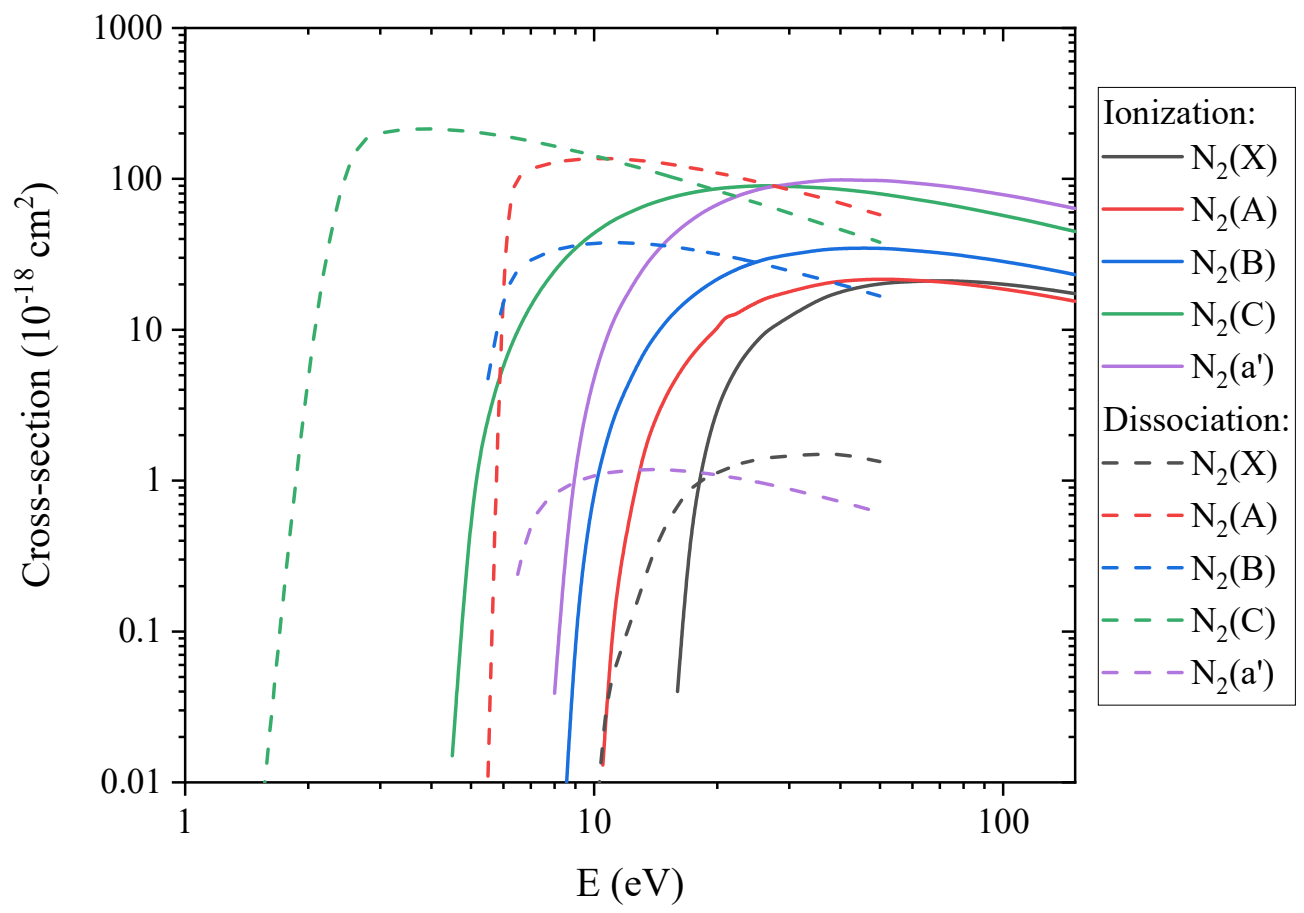

Fig. 9 Ionization and dissociation cross-sections by electron impact computed by Bacri and Medani [37]. The dissociation cross-section of $\mathrm{N}_{2}$ (a') is low compared to other excited states, whereas its ionization cross-section is similar.

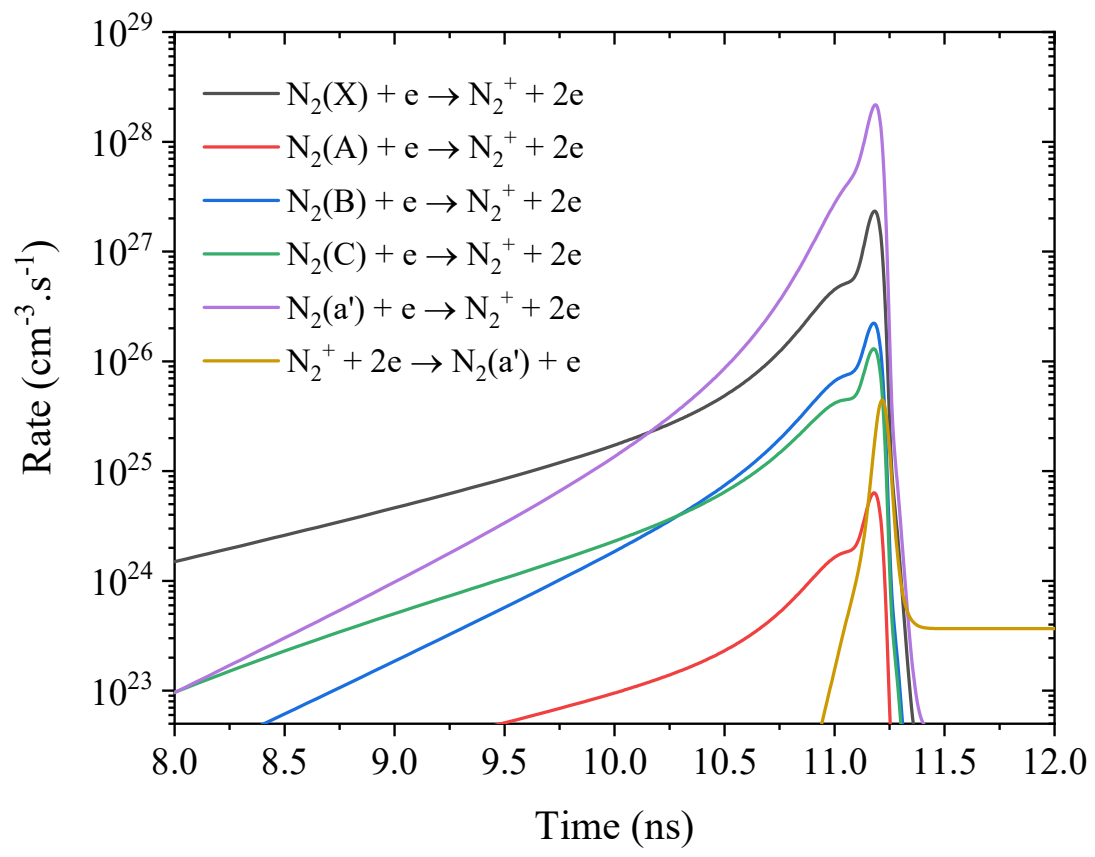

Fig. 10 Ionization rates of $\mathrm{N}_{2}\left(X, A, B, C, a^{\prime}\right)$. The net ionization rates (i.e. with recombination rate subtracted) is shown in Fig. 4 (purple solid curve). 


\section{References}

[1] Ju, Y., and Sun, W. "Plasma Assisted Combustion: Dynamics and Chemistry." Progress in Energy and Combustion Science, Vol. 48, 2015, pp. 21-83. doi:10.1016/j.pecs.2014.12.002.

[2] Pilla, G., Galley, D., Lacoste, D. A., Lacas, F., Veynante, D., and Laux, C. O. "Stabilization of a Turbulent Premixed Flame Using a Nanosecond Repetitively Pulsed Plasma." IEEE Transactions on Plasma Science, Vol. 34, No. 6, 2006, pp. 2471-2477. doi:10.1109/TPS.2006.886081.

[3] Pilla, G. Etude Expérimentale de La Stabilisation de Flammes Propane-Air de Prémélange Par Décharges Nanosecondes Impulsionnelles Répétitives. Ecole Centrale Paris, PhD Thesis, 2008.

[4] Barbosa, S., Pilla, G., Lacoste, D. A., Scouflaire, P., Ducruix, S., Laux, C. O., and Veynante, D. "Influence of Nanosecond Repetitively Pulsed Discharges on the Stability of a Swirled Propane/Air Burner Representative of an Aeronautical Combustor." Philosophical Transactions of the Royal Society A: Mathematical, Physical and Engineering Sciences, Vol. 373, No. 2048, 2015, p. 20140335. doi:10.1098/rsta.2014.0335.

[5] Lacoste, D. A., Moeck, J. P., Durox, D., Laux, C. O., and Schuller, T. "Effect of Nanosecond Repetitively Pulsed Discharges on the Dynamics of a Swirl-Stabilized Lean Premixed Flame." Journal of Engineering for Gas Turbines and Power, Vol. 135, No. 10, 2013, p. 101501. doi:10.1115/1.4024961.

[6] Pancheshnyi, S. V, Lacoste, D. A., Bourdon, A., and Laux, C. O. "Ignition of Propane-Air Mixtures by a Repetitively Pulsed Nanosecond Discharge.” IEEE Transactions on Plasma Science, Vol. 34, No. 6, 2006, pp. 2478-2487. doi:10.1109/TPS.2006.876421.

[7] Boumehdi, M. A., Stepanyan, S. A., Desgroux, P., Vanhove, G., and Starikovskaia, S. M. "Ignition of Methane- and n-Butane-Containing Mixtures at High Pressures by Pulsed Nanosecond Discharge." Combustion and Flame, Vol. 162, No. 4, 2015, pp. 1336-1349. doi:10.1016/J.COMBUSTFLAME.2014.11.006.

[8] Pai, D. Z., Stancu, G. D., Lacoste, D. A., and Laux, C. O. "Nanosecond Repetitively Pulsed Discharges in Air at Atmospheric Pressure - The Glow Regime.” Plasma Sources Science and Technology, Vol. 18, No. 4, 2009, p. 045030. doi:10.1088/0963-0252/18/4/045030.

[9] Pai, D. Z., Lacoste, D. A., and Laux, C. O. "Transitions between Corona, Glow, and Spark Regimes of Nanosecond Repetitively Pulsed Discharges in Air at Atmospheric Pressure.” Journal of Applied Physics, Vol. 107, No. 9, 2010, p. 093303. doi:10.1063/1.3309758.

[10] Pai, D. Z., Lacoste, D. A., and Laux, C. O. "Nanosecond Repetitively Pulsed Discharges in Air at Atmospheric Pressure-the Spark Regime.” Plasma Sources Science and Technology, Vol. 19, No. 6, 2010, p. 065015. doi:10.1088/0963-0252/19/6/065015.

[11] Rusterholtz, D. L., Lacoste, D. A., Stancu, G. D., Pai, D. Z., and Laux, C. O. "Ultrafast Heating and Oxygen Dissociation in Atmospheric Pressure Air by Nanosecond Repetitively Pulsed Discharges." Journal of Physics D: Applied Physics, Vol. 46, No. 46, 2013, p. 464010. doi:10.1088/0022$3727 / 46 / 46 / 464010$.

[12] Parkevich, E. V., Medvedev, M. A., Khirianova, A. I., Ivanenkov, G. V., Agafonov, A. V., Selyukov, A. S., Mingaleev, A. R., Shelkovenko, T. A., and Pikuz, S. A. "Investigation of a Near-Electrode Plasma Formed in the Atmospheric Discharge with Employment of Picosecond Laser Probing." Journal of Russian Laser Research, No. February, 2019. doi:10.1007/s10946-019-09769-5.

[13] Parkevich, E. V., Khirianova, A. I., Agavonov, A. V., Tkachenko, S. I., Mingaleev, A. R., Shelkovenko, T. A., Oginov, A. V., and Pikuz, S. A. "Anode Plasma Formation at the Initial Stage of a Nanosecond Air Discharge." Journal of Experimental and Theoretical Physics, Vol. 126, No. 3, 2018, pp. 422-429. doi:10.1134/S1063776118030160.

[14] Orrière, T., Moreau, E., and Pai, D. Z. "Ionization and Recombination in Nanosecond Repetitively Pulsed Microplasmas in Air at Atmospheric Pressure." Journal of Physics D: Applied Physics, Vol. 51, No. 49, 2018, p. 494002. doi:10.1088/1361-6463/aae134.

[15] Laux, C., Yu, L., Packan, D. M., Gessman, R. J., Pierrot, L., Kruger, C. H., and Zare, R. "Ionization Mechanisms in Two-Temperature Air Plasmas." 30th Plasmadynamic and Lasers Conference, No. 99 
3476, 1999. doi:10.2514/6.1999-3476.

[16] Lo, A., Cessou, A., Lacour, C., Lecordier, B., Boubert, P., Xu, D. A., Laux, C. O., and Vervisch, P. "Streamer-to-Spark Transition Initiated by a Nanosecond Overvoltage Pulsed Discharge in Air." Plasma Sources Science and Technology, Vol. 26, No. 4, 2017, p. 45012. doi:10.1088/1361-6595/aa5c78.

[17] Minesi, N., Stepanyan, S. A., Mariotto, P. B., Stancu, G.-D., and Laux, C. O. "On the Arc Transition Mechanism in Nanosecond Air Discharges.” AIAA Scitech 2019 Forum, 2019. doi:10.2514/6.2019-0463.

[18] Sainct, F. Etude de La Réactivité de Décharges Électriques Nanoseconde à La Pression Atmosphérique Dans La Vapeur d'eau. Ecole Centrale Paris, 2014.

[19] Houpt, A. W., and Leonov, S. B. "Charge Transfer in Constricted Form of Surface Barrier Discharge at Atmospheric Pressure." Journal of Thermophysics and Heat Transfer, Vol. 31, 2016, pp. 1-9. doi:10.2514/1.T4970.

[20] Shcherbanev, S. A., Yu Khomenko, A., Stepanyan, S. A., Popov, N. A., and Starikovskaia, S. M. "Optical Emission Spectrum of Filamentary Nanosecond Surface Dielectric Barrier Discharge." Plasma Sources Science and Technology, Vol. 26, No. 2, 2016, p. 02LT01. doi:10.1088/1361-6595/26/2/02LT01.

[21] Shcherbanev, S., Ding, C., Starikovskaia, S. M., and Popov, N. A. "Filamentary Nanosecond Surface Dielectric Barrier Discharge. Plasma Properties in the Filaments." Plasma Sources Science and Technology, 2019. doi:10.1088/1361-6595/ab2230.

[22] Stepanyan, S. A., Starikovskiy, A. Y., Popov, N. A., and Starikovskaia, S. M. "A Nanosecond Surface Dielectric Barrier Discharge in Air at High Pressures and Different Polarities of Applied Pulses: Transition to Filamentary Mode.” Plasma Sources Science and Technology, Vol. 23, No. 4, 2014, p. 045003. doi:10.1088/0963-0252/23/4/045003.

[23] Macheret, S. O., Shneider, M. N., and Miles, R. B. "Modeling of Air Plasma Generation by Repetitive High-Voltage Nanosecond Pulses.” IEEE Transactions on Plasma Science, Vol. 30, No. 3, 2002, pp. 1301-1314. doi:10.1109/TPS.2002.802142.

[24] Kossyi, I. A., Kostinsky, A. Y., Matveyev, A. A., and Silakov, V. P. "Kinetic Scheme of the NonEquilibrium Discharge in Nitrogen-Oxygen Mixtures." Plasma Sources Science and Technology, Vol. 1, No. 3, 1992, pp. 207-220. doi:10.1088/0963-0252/1/3/011.

[25] Capitelli, M., Ferreira, C. M., Gordiets, B. F., and Osipov, A. I. Plasma Kinetics in Atmospheric Gases. Springer Berlin Heidelberg, Berlin, Heidelberg, 2000.

[26] Biberman, L. M., Vorob'Ev, V. S., and Yakubov, I. T. "Kinetics of Impact-Radiation Ionization and Recombination." Soviet Physics - Uspekhi, Vol. 15, No. 4, 1973, pp. 375-394. doi:10.1070/PU1973v015n04ABEH004987.

[27] Bourdon, A., and Vervisch, P. "Three-Body Recombination Rate of Atomic Nitrogen in Low-Pressure Plasma Flows." Physical Review E - Statistical Physics, Plasmas, Fluids, and Related Interdisciplinary Topics, Vol. 54, No. 2, 1996, pp. 1888-1898. doi:10.1103/PhysRevE.54.1888.

[28] Park, C. "Comparison of Electron and Electronic Temperatures in Recombining Nozzle Flow of Ionized Nitrogen-Hydrogen Mixture. Part 2. Experiment.” Journal of Plasma Physics, Vol. 9, No. 2, 1973, pp. 217-234. doi:10.1017/S0022377800007443.

[29] Annaloro, J., Morel, V., Bultel, A., and Omaly, P. "Global Rate Coefficients for Ionization and Recombination of Carbon, Nitrogen, Oxygen, and Argon.” Physics of Plasmas, Vol. 19, No. 7, 2012. doi:10.1063/1.4737147.

[30] Pancheshnyi, S. V, Eismann, B., Hagelaar, G. J. M., and Pitchford, L. C. Computer Code ZDPlasKin. http://www.zdplaskin.laplace.univ-tlse.fr.

[31] Flitti, A., and Pancheshnyi, S. "Gas Heating in Fast Pulsed Discharges in N 2 -O 2 Mixtures." The European Physical Journal Applied Physics, Vol. 45, No. 2, 2009, p. 21001. doi:10.1051/epjap/2009011.

[32] Hagelaar, G. J. M., and Pitchford, L. C. "Solving the Boltzmann Equation to Obtain Electron Transport Coefficients and Rate Coefficients for Fluid Models." Plasma Sources Science and Technology, Vol. 14, No. 4, 2005, pp. 722-733. doi:10.1088/0963-0252/14/4/011. 
[33] www.lxcat.net, retrieved on April 4, 2019. BSR Database. .

[34] www.lxcat.net, retrieved on March 1, 2019. IST-Lisbon Database. .

[35] www.lxcat.net, retrieved on March 1, 2019. Hayashi Database. .

[36] www.lxcat.net, retrieved on March 1, 2019. Morgan Database. .

[37] Bacri, J., and Medani, A. "Electron Diatomic Molecule Weighted Total Cross Section Calculation. III. Main Inelastic Processes for N2 and N+ 2." Physica B+C, Vol. 112, No. 1, 1982, pp. 101-118. doi:10.1016/0378-4363(82)90136-X.

[38] Biberman, L. M., Vorob'ev, V. S., Yakubov, I. T., and Cecchi, J. L. "Kinetics of Nonequilibrium LowTemperature Plasmas.” Physics Today, Vol. 42, No. 4, 1989, pp. 65-66. doi:10.1063/1.2810978.

[39] Wang, Y., Zatsarinny, O., and Bartschat, K. "B-Spline R-Matrix-with-Pseudostates Calculations for Electron-Impact Excitation and Ionization of Nitrogen." Physical Review A, Vol. 89, No. 6, 2014, p. 062714. doi:10.1103/PhysRevA.89.062714.

[40] Tayal, S. S., and Zatsarinny, O. "B -Spline R -Matrix-with-Pseudostates Approach for Excitation and Ionization of Atomic Oxygen by Electron Collisions.” Physical Review A, Vol. 94, No. 4, 2016, pp. 115. doi:10.1103/PhysRevA.94.042707.

[41] Ciccarino, C. J., and Savin, D. W. "Electron-Impact Ionization of Atomic Nitrogen." Journal of Thermophysics and Heat Transfer, Vol. 33, No. 1, 2019, pp. 154-162. doi:10.2514/1.T5463.

[42] Popov, N. A. "Investigation of the Mechanism for Rapid Heating of Nitrogen and Air in Gas Discharges." Plasma Physics Reports, Vol. 27, No. 10, 2002, pp. 886-896. doi:10.1134/1.1409722.

[43] Parkevich, E., Medvedev, M., Ivanenkov, G., Khirianova, A., Selyukov, A., Agafonov, A., Korneev, P., Gus'kov, S., and Mingaleev, A. "Fast Fine-Scale Spark Filamentation and Its Effect on the Spark Resistance.” Plasma Sources Science and Technology, 2019. doi:10.1088/1361-6595/ab3768. 